\title{
Conversion of Corn Cobs Waste into Activated Carbons for Adsorption of Heavy Metals from Minerals Processing Wastewater
}

\author{
William Buah ${ }^{1, *}$, Jennifer MacCarthy ${ }^{2}$, Samuel Ndur ${ }^{2}$ \\ ${ }^{1}$ Minerals Engineering Department, University of Mines and Technology, Tarkwa, Ghana \\ ${ }^{2}$ Environmental and Safety Engineering Department, University of Mines and Technology, Tarkwa, Ghana \\ Email address: \\ wkbuah@yahoo.com (W.Buah) \\ ${ }^{*}$ Corresponding author
}

\section{To cite this article:}

William Buah, Jennifer MacCarthy, Samuel Ndur. Conversion of Corn Cobs Waste into Activated Carbons for Adsorption of Heavy Metals from Minerals Processing Wastewater. International Journal of Environmental Protection and Policy. Vol. 4, No. 4, 2016 , pp. $98-103$. doi: $10.11648 /$ j.ijepp.20160404.11

Received: June 7, 2016; Accepted: June 15, 2016; Published: June 29, 2016

\begin{abstract}
This study investigated adsorption of Lead $\left(\mathrm{Pb}^{2+}\right)$, Copper $\left(\mathrm{Cu}^{2+}\right)$ and Cadmium $\left(\mathrm{Cd}^{2+}\right)$ from minerals processing wastewater using activated carbons prepared from waste corn cobs. The activated carbons were prepared by carbonisation of the waste at $900^{\circ} \mathrm{C}$ to obtain carbonised corn cobs. Samples of the carbonised material were activated at $900^{\circ} \mathrm{C}$ for various durations using steam as an activating agent. The derived activated carbons were contacted with the wastewater containing heavy metals to assess their heavy metal removal abilities. From the results, up to $99.9 \%, 99.8$ and $99.7 \%$ adsorption were attained for $\mathrm{Pb}^{2+}, \mathrm{Cu}^{2+}$ and $\mathrm{Cd}^{2+}$ respectively. This reduced the concentrations of $\mathrm{Pb}^{2+}, \mathrm{Cu}^{2+}$ and $\mathrm{Cd}^{2+}$ from $1.56 \mathrm{mg} / \mathrm{L}, 1.87$ $\mathrm{mg} / \mathrm{L}$ and $0.69 \mathrm{mg} / \mathrm{L}$, respectively, to $<0.002 \mathrm{mg} / \mathrm{L}$ for each metal ion. The results demonstrate that the derived activated carbons have the capacity to significantly reduce heavy metal concentrations to levels below the World Health Organisation (WHO) standards for safe drinking water.
\end{abstract}

Keywords: Corn Cob, Activated Carbon, Heavy Metal, Wastewater and Adsorption

\section{Introduction}

Maize is a popular cereal crop cultivated in many parts of the world [1]. During the processing and production of corn, several wastes are generated including corn cobs and corn husk. The world production of corn increased in the 1980s, which also implies a high amount of corn cob waste. In Ghana, where this study was carried out, corn production increased from 346,000 tonnes in 1982 to $1,800,000$ tonnes in 2015 . It is estimated that about $18 \mathrm{~kg}$ of cobs are obtained from every $100 \mathrm{~kg}$ of corn produced [2]. The corn cobs are regarded as carbonaceous materials but a greater percentage of it, for example in Ghana, ends up in landfills as waste.

In recent times, various low-cost activated carbons derived from carbonaceous agricultural wastes [3], including coconut shells [4], palm kernel shells [5], chickpea husks [6] and corn cobs [2] are used as adsorbents for gases and liquid phase pollutants. Treatment of water in Ghana is done by several processes such as ion exchange, chemical precipitation and solvent extraction. However, these processes are very selective and expensive.

Since water continues to be an essential supporter of all forms of plant and animal life, there is the need for treatment when it gets polluted, especially with heavy metals. The main threats to human health from heavy metals are associated with exposure to lead, cadmium, mercury and arsenic. These metals have been extensively studied and their effects on human health regularly reviewed by international bodies such as the World Health Organization (WHO). For example, cadmium represents a health risk via accumulation in living tissue and has been associated with an increased risk of lung cancer, emphysema, kidney damage and in extreme circumstances, damage to bones and joints [7-9]. Mercury and mercury compounds give rise to toxic effects associated with the central nervous system, the major areas affected 
being associated with the sensory, and auditory functions as well as those concerned with co-ordination [10]. Lead exposure has been associated with dysfunction in the haematological system and central nervous system. Decrease in intelligence and behaviour have been reported in children exposed to increased levels of lead [10-14].

Treatment of water in some parts of Ghana using imported activated carbon is not economical due to high cost of importation. Local production of activated carbon, with the ability to remove heavy metals from waste water cannot be overemphasized.

This paper is aimed at the development of activated carbons from corn cobs and assessment of their efficiency for removing heavy metals from polluted minerals processing wastewater. A two-step activation process: carbonisation of samples of corn cobs followed by steam activation of the derived char at various durations of activation was used to obtain activated carbons of different surface areas and pore characteristics. The activated carbons were contacted with a solution containing appreciable levels of heavy metals to assess their heavy metal adsorption efficiencies.

\section{Materials and Methods}

\subsection{Materials Preparation and Analysis}

The corn cobs used in this work were gathered from a farm located in Koforidua, the Regional capital of the Eastern Region of Ghana. The corn cobs which contained sand were washed thoroughly to remove all the sand which could influence the final composition of the material. This was followed by drying at $110^{\circ} \mathrm{C}$ in an oven till constant weight was achieved before carbonisation. Proximate and ultimate analyses of a sample of the corn cobs, pulverised to $-1 \mathrm{~mm}$ were determined using thermogravimetric analysis (TGA) in a Shimadzu TGA-50 H.

De-ionised water from the Minerals Engineering Laboratory of the University of Mines and Technology, Tarkwa, Ghana was used as the activation agent.

Wastewater sample used for the adsorption studies was collected from a stream in the Tarkwa environment. A plastic sample bottle was washed and well rinsed with distilled water before sampling. The sample bottle was submerged in the stream to a depth of about $0.5 \mathrm{~m}$, opened, filled, corked and then removed. The water sample was immediately placed in an 'ice chest' in ice packs and transported to the laboratory for analyses within six hours using a Varian Fast Sequential Atomic Adsorption Spectrophotometer (Varian AA 240 FS).

\subsection{Preparation of Activated Carbons from the Corn Cobs}

Activation of the corn cobs was carried out in two steps. In the first step, the washed and dried cobs were carbonised in a gas fired static bed pyrolysis-activation reactor, designed and fabricated in Ghana [15], at $900^{\circ} \mathrm{C}$ pyrolysis temperature. This reactor has a stainless steel chamber of a rectangular cross-section, having a square groove positioned symmetrically at the bottom part of the reactor, which allows efficient heat transfer into the bed of material being pyrolysed. The design allows easy feeding of precursors as well as easy discharging of carbonised products [15]. The pyrolysis derived char was kept at the final pyrolysis temperature for $60 \mathrm{~min}$ to ensure pyrolysis is carried to completion as much as possible and then allowed to cool. The second step involved physical activation of the char samples at $900^{\circ} \mathrm{C}$ activation temperature using steam as the activation agent. The activation was done for $1.0 \mathrm{~h}, 2.0 \mathrm{~h}, 2.5$ $\mathrm{h}$ and $3.0 \mathrm{~h}$ at a water flow rate of $0.2 \mathrm{~mol} / \mathrm{h} / \mathrm{g}$. The activation procedure was repeated thrice for each time (duration) to assess the repeatability of the yields of the activated carbons.

\subsection{Determination of Specific Surface Areas and Pore Volumes of the Activated Carbons}

The determination of the specific surface area was done by the Brunauer, Emmett, and Teller (BET) method [16]. In this determination, adsorption of nitrogen by the activated carbons was carried out at $77 \mathrm{~K}$ using a Micromeritics TriStar 3000 apparatus. The BET surface area assessment was done by applying relative pressures ranging from 0.05 to 0.20 . The total pore volumes of the derived activated carbons were estimated to be the liquid volumes of $\mathrm{N}_{2}$ at a high relative pressure of 0.96 , assuming the molecular cross-sectional area of nitrogen to be $0.162 \mathrm{~nm}^{2}$. The micropore volumes were calculated by applying the Dubinin Radushkevich (DR) equation to the nitrogen adsorption isotherms of the activated carbons [17]. The surface areas and pore volumes determinations were repeated for each sample.

\subsection{Heavy Metal Adsorption Studies of the Activated Carbons}

Adsorption experiment for each batch of activated carbons was done by contacting $500 \mathrm{~mL}$ of the contaminated water with $25 \mathrm{~g}$ of the previously prepared activated carbon in a bevelled glass bottle. The bottles and contents were placed on a roller and rotated at $150 \mathrm{rpm}$ at a room temperature of $\left(32^{\circ} \mathrm{C}\right)$ for a period of $60 \mathrm{~min}$. Samples were taken from the bottles every 5 to $15 \mathrm{~min}$. The solution samples were filtered using Whatman filter paper $(0.45 \mu \mathrm{m}$ pore size $)$. A Varian Fast Sequential Atomic Adsorption Spectrophotometer (Varian AA 240 FS) was then used to analyse the concentrations of the metal ions present in the filtrate.

\section{Results and Discussion}

\subsection{Properties of Materials Used}

The corn cobs contained $19.50 \mathrm{wt} \%$ fixed carbon, 68.62 $\mathrm{wt} \%$ volatile matter, $4.41 \mathrm{wt} \%$ ash and $5.23 \mathrm{wt} \%$ moisture. The carbon, hydrogen and nitrogen contents were also analysed using a FlashEA 1112 analyser as $44.57 \mathrm{wt} \%, 6.26$ $\mathrm{wt} \%$ and $1.30 \mathrm{wt} \%$, respectively.

The Atomic Adsorption Spectrophotometer analysis of the wastewater detected the concentration of $\mathrm{Pb}^{2+}, \mathrm{Cu}^{2+}$ and $\mathrm{Cd}^{2+}$ as $1.56 \mathrm{mg} / \mathrm{L}, 1.87 \mathrm{mg} / \mathrm{L}$ and $0.69 \mathrm{mg} / \mathrm{L}$, respectively. The $\mathrm{pH}$ of the wastewater was 6 . 


\subsection{Activated Carbons Obtained from the Corn Cobs}

Carbonisation of $2700 \mathrm{~g}$ of the fresh corn cobs resulted in the production of $646 \mathrm{~g}$ carbonised material (char). The fresh corn cobs and corresponding char obtained after carbonisation are shown in Figs. $1 \mathrm{a}$ and $1 \mathrm{~b}$, respectively. The figures show that the char retained the form and structure of the fresh cobs as received. Unlike in related research studies [18] the cobs were not shredded.

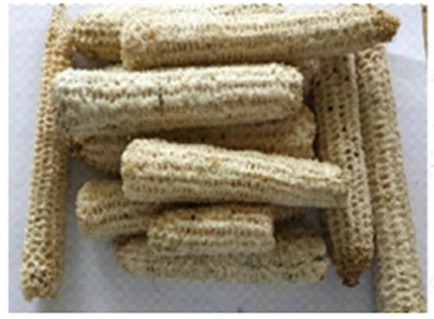

(a)

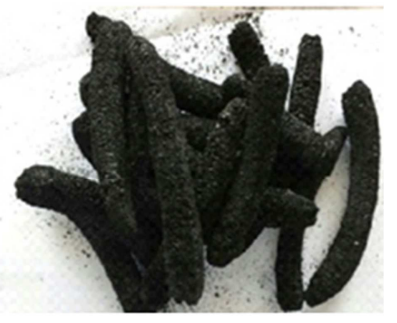

(b)
Fig. 1. Corn Cobs: (a) Before carbonisation (b) After carbonisation at $900^{\circ} \mathrm{C}$ pyrolysis temperature.

They were carbonised and activated as received because the authors envisaged that the fibrous structure of the cobs retained after the activation will allow infiltration of liquids to ensure adsorption at the active sites of the products. The result of carbonisation shows that the yield of char obtained compares well with that obtained by other researchers. For example, Kaźmierczak et al. [2] also studied sorption properties of activated carbons obtained from corn cobs by chemical and physical activation. In their work, a sample of corn cobs was heated from room temperature to a final pyrolysis temperature of $800^{\circ} \mathrm{C}$. The sample was kept at the final pyrolysis temperature for $60 \mathrm{~min}$ and then cooled. The yield of char obtained was $16.6 \mathrm{wt} \%$.

The yields of activated carbons obtained after various durations of activation are shown in Fig. 2. The results show a decrease in yield of activated carbons with increasing activation time. For example, the yield of the unactivated char reduced from $100 \mathrm{wt} \%$ (duration of activation =0) to $72.81 \mathrm{wt} \%$ after $3 \mathrm{~h}$ of activation. There was a good repeatability of the yields of the derived activated carbons.

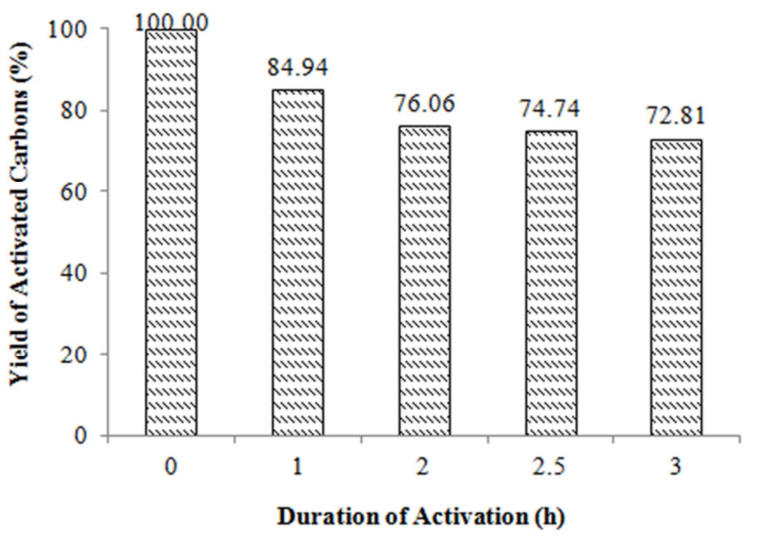

Fig. 2. Influence of duration of activation on the yield of the activated carbons produced from the corn cobs at $900^{\circ} \mathrm{C}$ activation temperature.

This trend can be explained by the fact that carbon gasification is enhanced by increase in activation temperature and extended activation time [19-23]. Increasing activation temperature and time leads to increased carbon-activation reagent reaction and, consequently, increase in the degree of carbon burn-off and decrease in yield [19, 21-23].

\subsection{Surface Areas and Pore Volumes of the Activated Carbons}

Table 1 shows the BET surface areas of the activated carbons produced by steam activation at $900^{\circ} \mathrm{C}$ activation temperature and various durations of activation of the chars obtained from the pyrolysis stage.

The BET surface areas of the activated carbons ranged between $510.10 \mathrm{~m}^{2} / \mathrm{g}$ and $631.15 \mathrm{~m}^{2} / \mathrm{g}$ for various durations of activation ranging from $1 \mathrm{~h}$ to $3 \mathrm{~h}$.

From the results in Table 1, the BET surface areas of the activated carbons produced in this work are well within the range reported in literature for various precursors. For example, Kaźmierczak et al. [2] pyrolysed corn cobs at $500^{\circ} \mathrm{C}$ and $800^{\circ} \mathrm{C}$ and subjected the resulting chars to physical activation using carbon dioxide as the activating agent. The specific surface area of the activated carbon obtained from the $500^{\circ} \mathrm{C}$ pyrolysis derived char was $352 \mathrm{~m}^{2} / \mathrm{g}$ and that of the $800^{\circ} \mathrm{C}$ pyrolysis derived char was $566 \mathrm{~m}^{2} / \mathrm{g}$.

Table 1. Surface area and pore volumes of the activated carbons produced from corn cobs at $900^{\circ} \mathrm{C}$ activation temperature and various durations.

\begin{tabular}{lllll}
\hline Activation time $(\mathbf{h})$ & BET surface area $\left(\mathrm{m}^{\mathbf{2}} / \mathbf{g}\right)$ & Total pore volume $\left(\mathrm{m}^{\mathbf{3}} / \mathbf{g}\right)$ & Micro pore volume $\left(\mathrm{m}^{\mathbf{3}} / \mathbf{g}\right)$ & $\mathbf{M e s o p o r e ~ v o l u m e ~}\left(\mathrm{m}^{\mathbf{3}} / \mathbf{g}\right)$ \\
\hline 0.0 & 45.03 & undetermined & undetermined \\
1.0 & 500.10 & 0.25 & 0.25 & 0.00 \\
2.0 & 600.00 & 0.29 & 0.27 & 0.02 \\
2.5 & 613.45 & 0.31 & 0.29 & 0.02 \\
3.0 & 631.15 & 0.32 & 0.29 \\
\hline
\end{tabular}

The pore volumes of the derived activated carbons ranging between $0.25-0.32 \mathrm{~m}^{3} / \mathrm{g}$ were also within the ranges reported in literature. For example, Daud et al. [5] studied pore development in palm kernel shell based activated carbon. In their work activation was carried out in a fluidised bed reactor at $820^{\circ} \mathrm{C}$ and micropore volumes of the derived activated carbons ranging between $0.25-0.6 \mathrm{~cm}^{3} / \mathrm{g}$ were recorded. Similarly, the pore volumes of the activated carbons obtained by pyrolysis of corn cobs at $500^{\circ} \mathrm{C}$ and $800^{\circ} \mathrm{C}$ followed by activation of the pyrolysis derived chars at $800^{\circ} \mathrm{C}$ using carbon dioxide as the activating agent were $0.19 \mathrm{~m}^{3} / \mathrm{g}$ and $0.30 \mathrm{~m}^{3} / \mathrm{g}$, respectively [2].

Again, a very good repeatability of the surface areas and pore volumes of the activated carbons obtained under similar conditions were observed. 


\subsection{Metals Ions Adsorption}

The metal ions in the wastewater analysed during this research were $\mathrm{Pb}^{2+}, \mathrm{Cu}^{2+}$ and $\mathrm{Cd}^{2+}$ with initial concentrations $1.57,1.87$ and $0.69 \mathrm{mg} / \mathrm{L}$, respectively. The results of the adsorption of $\mathrm{Pb}^{2+}, \mathrm{Cu}^{2+}$ and $\mathrm{Cd}^{2+}$ by the various corn cob activated carbons are presented in Figs. 3 to 5 .

\subsubsection{Adsorption of Lead}

From Fig. 3 a, the concentrations of $\mathrm{Pb}^{2+}$ in solution decreased sharply in the first $15 \mathrm{~min}$ of adsorption and thereafter adsorption slowed down. Fig. $3 \mathrm{~b}$ is an expanded version of the lower concentration $(<0.15 \mathrm{ppm})$ region of Fig. $3 \mathrm{a}$, in order to make the relative adsorption abilities of the carbons derived after various durations of activation more legible.
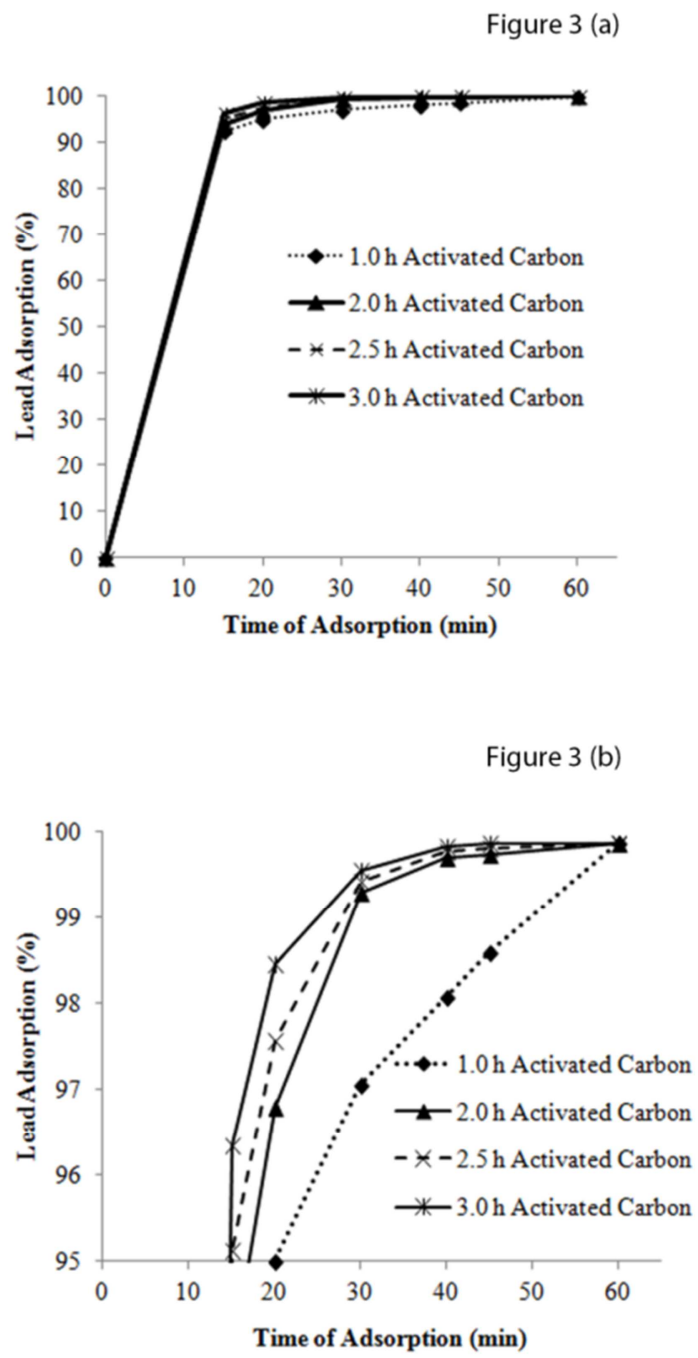

Fig. 3. Influence of adsorption time on adsorption of Lead in the wastewater by the activated carbons produced at $900^{\circ} \mathrm{C}$ activation temperature and various durations of activation: (a) For 0 to 1.57 ppm of Lead concentration (b) For 0 to 0.15 ppm of Lead concentration..

While the activated carbon obtained after $3.0 \mathrm{~h}$ activation adsorbed up to $99.6 \% \mathrm{~Pb}^{2+}$ after $30 \mathrm{~min}$, that obtained after $1 \mathrm{~h}$ adsorbed up to $97.1 \%$ within the same period. It took about 50 min for the $1 \mathrm{~h}$ activated carbon to adsorb up to $99.0 \%$. The results in Table 1 show that the surface areas and pore volumes increased with activation time. It can therefore be inferred that the rate of adsorption of the metal ion was a function of the pore volumes and internal surface areas developed during the activation process. The performance of the locally produced corn cobs activated carbon for lead removal is encouraging compared with results of similar tests elsewhere [9, 24-25]. For example, Bernard et al. [9] achieved $80 \%$ removal of $\mathrm{Pb}^{2+}$ from industrial wastewater by activated carbon prepared from coconut shells after $30 \mathrm{~min}$ of adsorption.

The 99.6\% adsorption of $\mathrm{Pb}^{2+}$ after 30 min of adsorption by the $3.0 \mathrm{~h}$ activated carbon left a residual $\mathrm{Pb}^{2+}$ concentration of $0.006 \mathrm{mg} / \mathrm{L}$, which is below the WHO threshold of $0.01 \mathrm{mg} / \mathrm{L}$ for safe drinking water.

\subsubsection{Adsorption of Copper}

The initial $\mathrm{Cu}^{2+}$ concentration in the wastewater used for this study was below the WHO threshold of $2 \mathrm{mg} / \mathrm{L}$ for safe drinking water. Fig. 4 shows adsorption of $\mathrm{Cu}^{2+}$ from the wastewater in relation to adsorption time. The activated carbons reduced the concentration $\mathrm{Cu}^{2+}$ from $1.87 \mathrm{mg} / \mathrm{L}$ to less than $0.03 \mathrm{mg} / \mathrm{L}$ in $15 \mathrm{~min}$, attaining over $98.4-99.0 \%$ adsorption.

Figure $4(a)$

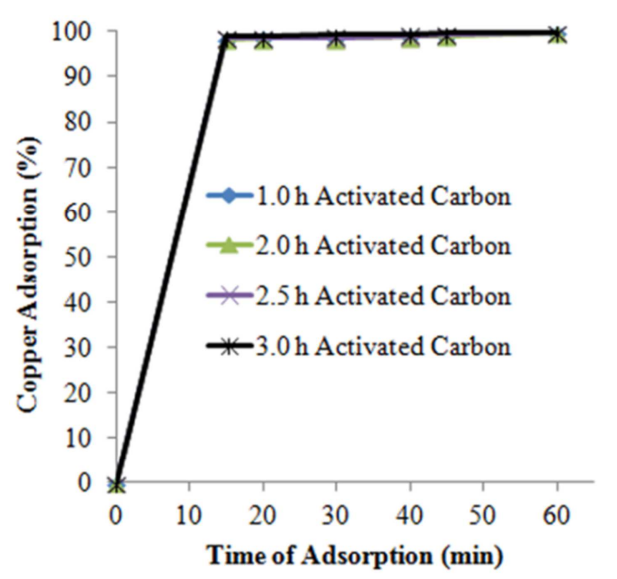

Figure 4 (b)

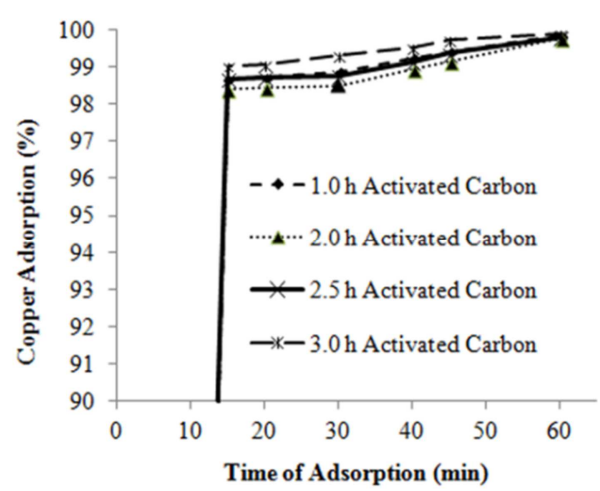

Fig. 4. Influence of adsorption time on adsorption of Copper in the wastewater by the activated carbons produced at $900^{\circ} \mathrm{C}$ activation temperature and various durations of activation: (a) For 0 to $1.87 \mathrm{ppm}$ of Copper concentration (b) For 0 to 0.15 ppm of Copper concentration. 
Fig. $4 \mathrm{~b}$ is an expanded version of the lower concentration $(<0.15 \mathrm{ppm})$ region of Fig. 4 a, to make the relative adsorption abilities of the carbons derived after various durations of activation more legible. The figure shows that the rate of adsorption of $\mathrm{Cu}^{2+}$ was found to be a function of the pore volumes and internal surface areas developed during the activation process. Here, it was established that increase in surface area and pore volumes of the activated carbons resulted in increased adsorption.

\subsubsection{Adsorption of Cadmium}

Fig. 5 shows adsorption of $\mathrm{Cd}^{2+}$ from the wastewater by the various activated carbons in relation to adsorption time

Figure 5 (a)

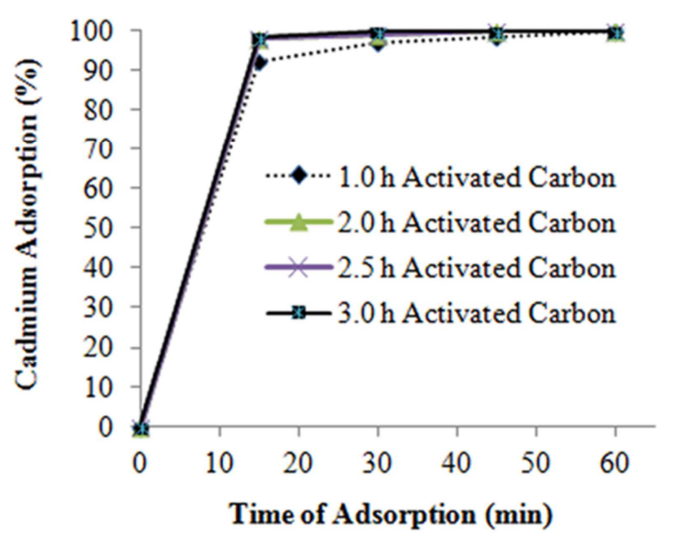

Figure 5 (b)

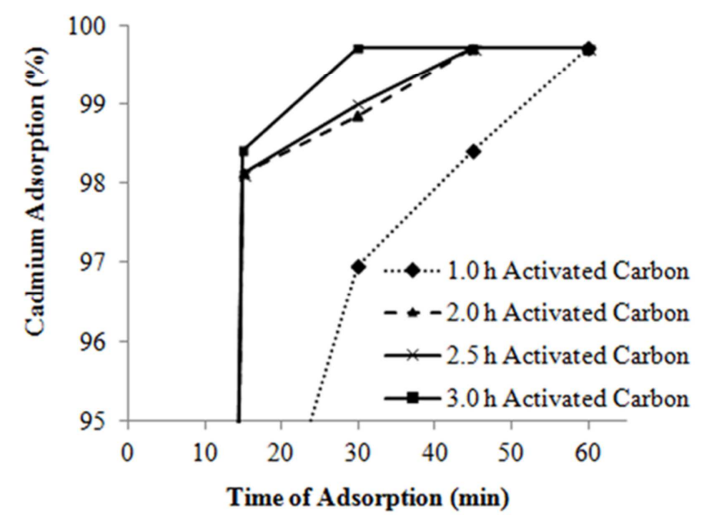

Fig. 5. Influence of adsorption time on adsorption of Cadmium in the wastewater by the activated carbons produced at $900^{\circ} \mathrm{C}$ activation temperature and various durations of activation: (a) For 0 to $0.69 \mathrm{ppm}$ of Cadmium concentration (b) For 0 to 0.15 ppm of Cadmium concentration.

The initial concentration of cadmium in the wastewater of $0.69 \mathrm{mg} / \mathrm{L}$ decreased sharply in the first $15 \mathrm{~min}$. After that period, adsorption slowed down. Adsorption of $99.7 \% \mathrm{Cd}^{2+}$ was achieved after $45 \mathrm{~min}$ of adsorption leaving a residual $\mathrm{Cd}^{2+}$ concentration of $0.002 \mathrm{mg} / \mathrm{L}$, which is below the WHO threshold of $0.003 \mathrm{mg} / \mathrm{L}$ for safe drinking water.

The adsorption of $\mathrm{Cd}^{2+}$ was also found to depend on the pore volumes and internal surface areas of the derived activated carbons. Here also, the adsorption performance of the activated carbons increased with the duration of activation. Again, this can be attributed to the increase in their surface area and pore volumes with increase in activation time.

\section{Conclusions}

Activated carbons of varrying specific surface areas and pore volumes were successfully prepared locally from corn cobs. The activated carbons can be used for removal of heavy metals such as $\mathrm{Pb}^{2+}, \mathrm{Cu}^{2+}$ and $\mathrm{Cd}^{2+}$ from wastewater. Adsorption of the heavy metals by the derived activated carbons was fastest within the first $15 \mathrm{~min}$ of adsorption and depended on the surface areas and pore volumes of the derived activated carbons. Since corn cobs are regarded as waste and readily available in Ghana, this study provides a more cost effective means of removing metal ions from contaminated water.

\section{Acknowledgment}

The support of the Government of Ghana via a Ghana Education Trust Fund (GETFund) Scholarship is gratefully acknowledged.

\section{References}

[1] M. L. Morris, R. Tripp and A. A. Dankyi, "Adoption and Impacts of Improved Corn Production Technology: A Case Study of the Ghana Grains Development Project", Economics Program Mexico, DF, CIMMYT, 1999, pp. 99-100.

[2] J. Kaźmierczak, P. Nowicki and R. Pietrzak, "Sorption properties of activated carbons obtained from corn cobs by chemical and physical activation", Adsorption, 2013, 19: 273281 .

[3] M. A. Yahya, Z. Al-Qodah and C. W. Zanariah Ngah, "Agricultural bio-waste materials as potential sustainable precursors used for activated carbon production: A review", Ren. and Sustain. Energy Reviews, 2015, 46: 218-235.

[4] Z. Hu and M. P. Srinivasan, "Preparation of High-SurfaceArea Activated Carbons from Coconut Shell", Microporous and Mesoporous Materials, 1999, 27: 11-18.

[5] W. M. Daud, W. S. Ali and M. Z. Suleiman, "The Effects of Carbonization Temperature on Pore Development in PalmShell-Based Activated Carbon", Carbon, 2000, 41: 19251932.

[6] J. Hayashi, A. Kazehaya, K. Muroyama and A. P. Watkinson, "Preparation of Activated Carbon from Lignin by Chemical Activation", Carbon, 1999, 38: 1873-1878.

[7] S. D. Probert, K. Kerr and J, Brown, "Harnessing energy from domestic, municipal and industrial refuse", Applied Energy, 1987, 27: 89-168.

[8] A. Bernard, "Cadmium and its adverse effects on human health", Indian J. Med. Res., 2008, 128: 557-64. 
[9] E. Bernard, A. Jimoh and J. O. Odigure, "Heavy Metals Removal from Industrial Wastewater by Activated Carbon Prepared from Coconut Shell", Research Journal of Chemical Sciences, 2013, 3: 3-9.

[10] World Health Organization, "Heavy metals and PAH compounds from municipal incinerators", Environmental Health Series, No. 32, World Health Organization, Copenhagen, 1990.

[11] S. Hou, L. Yuan, P. Jin, B. Ding, et al., "A clinical study of the effects of lead poisoning on the intelligence and neurobehavioral abilities of children", Theoretical Biology \& Medical Modelling, 2013, 10: 10-13.

[12] P. T. Williams, "Waste Treatment and Disposal", $2^{\text {nd }}$ Edition. John Wiley \& Sons Ltd, Chichester, UK, 2005, 380 pp.

[13] C. E. Gimba, G. I. Ndukwe, E. D. Paul et al., "Heavy Metals $(\mathrm{Cd}, \mathrm{Cu}, \mathrm{Fe}, \mathrm{Mn}$ and $\mathrm{Zn})$ Assessment of Groundwater in Kaltungo LGA, Gombe State, Nigeria", International Journal of Science and Technology, 2015, 4: 44-49.

[14] M. A. Momodu and C. A. Anyankora, "Heavy Metal Contamination of Ground Water", Journal of Environmental and Earth Science, 2010, 2: 39-43.

[15] W. K. Buah, J. S. Y. Kuma and P. T. Williams, "Activated Carbon Prepared in a Novel Gas Fired Static Bed PyrolysisGasification/Activation Reactor for Gold Di-Cyanide Adsorption", in $3^{\text {rd }}$ UMaT Biennial International Mining and Mineral Conference, 2014, pp. 243-250.

[16] S. J. Gregg and K. S. W. Sing, "Adsorption, Surface Area and Porosity”, Academic Press, London, 1982.

[17] M. M. Dubinin, and L. V. Radushkevitch, 1947 Proc. Acad. Sci. USSR, 55: 331.

[18] A. Ismail, D. B. Adie, I. A. Oke et al., “Adsorption kinetics of cadmium ions onto powdered corn cobs", The Canadian Journal of Chemical Engineering, 2009, 87: 896-909.

[19] H. Teng and S. C. Wang, "Preparation of porous carbon from phenol-formaldehyde resins with chemical and physical activation", Carbon, 2000, 38: 817-824.

[20] A. M. Cunliffe and P. T. Williams, "Influence of Process Conditions on the rate of Activation of Chars Derived from Pyrolysis of Used Tires”, Energy and Fuel, 1999 13: 166-175.

[21] A. C. Arampatzidou and E. A. Deliyanni, "Comparison of activation media and pyrolysis temperature for activated carbons development by pyrolysis of potato peels for effective adsorption of endocrine disruptor bisphenol, A. Journal of Colloid and Interface Science, 2016, 466: 101-112.

[22] A. B. Bogeat, M. Alexandre-Franco, C. Fernández-González et al., "Temperature dependence of the electrical conductivity of activated carbons prepared from vine shoots by physical and chemical activation methods", Microporous and Mesoporous Materials, 2015 209: 90-98.

[23] A. Martínez de Yuso, B. Rubio and M. T. Izquierdo, "Influence of activation atmosphere used in the chemical activation of almond shell on the characteristics and adsorption performance of activated carbons", Fuel Processing Technology, 2014, 119: 74-80.

[24] M. Karnib, A. Kabbani, H. Holail and Z. Olama, "Heavy Metals Removal Using Activated Carbon, Silica and Silica Activated Carbon Composite", Energy Procedia, 2014, 50: 113-120.

[25] S. Z. Mohammadi, H. Hamidian and Z. Moeinadini, "High surface area-activated carbon from Glycyrrhiza glabra residue by $\mathrm{ZnCl}_{2}$ activation for removal of $\mathrm{Pb}$ (II) and $\mathrm{Ni}$ (II) from water samples", J Industrial and Engineering Chemistry, 2014, 20: 4112-4118. 